\title{
ANALISIS TINGKAT KEKASARAN PERMUKAAN PADA HASIL PEMESINAN MESIN MILLING DENGAN VARIASI TINGGI PENCEKAMAN BENDA KERJA DAN TINGGI PEMASANGAN ENDMILL CUTTER
}

\author{
Zainuddin \\ Jurusan Teknik Mesin, Politeknik Negeri Bandung \\ J1. Gegerkalong Hilir, Ciwaruga, Parongpong, Kabupaten Bandung Barat, Jawa Barat 40559
}

Email: zainuddin060590@gmail.com

\begin{abstract}
ABSTRAK
Studi ini ditujukan untuk mengetahui tekstur permukaan dari proses pemesinan dengan beberapa variasi posisi. Posisi yang diuji dalam penelitian ini adalah posisi tinggi pencekaman endmill dan posisi pencekaman specimen.

Menurut penelitian-penelitian yang terdahulu, variabel yang menyebabkan kekasaran permukaan adalah penggunaan variasi parameter pemesianan, jenis perlakuan pemesinan yang kurang optimal dan geometri pahat. Oleh karena itu, penelitian ini mengambil variabel perlakuan posisi dan pencekaman baik spesimen maupun pemasangan endmill untuk mengetahui kondisi paling optimal terhadap tingkat kekasaran permukaan.

Hasil Penelitian ini didapatkan Tingkat kekasaran pada tinggi pencekaman endmill menunjukkan bahwa semakin mendekati flute maka akan semakin kasar karena ada rongga flute yang tidak tercekam, dan pencekaman semakin ke atas dari panjang endmill juga akan semakin kasar karena terjadi vibrasi yang besar saat proses pemakanan, rekomendasi dari penelitian ini agar mendapat nilai kekasaran yang optimal adalah memasang pahat di antara batas tengah panjangnya endmill sampai ke batas flute pada endmill.
\end{abstract}

Kata kunci: milling, endmill, kekasaran permukaan, pencekaman.

\section{PENDAHULUAN}

Pengerjaan logam dalam dunia manufacturing ada beberapa macam, mulai dari pengerjaan panas, pengerjaan dingin hingga pengerjaan logam secara mekanik. Pengerjaan mekanik logam biasanya digunakan untuk pengerjaan lanjutan maupun finishing, sehingga dalam pengerjaan mekanik dikenal beberapa prinsip pengerjaan, salah satunya adalah pengerjaan perataan permukaan dengan menggunakan mesin frais atau biasa disebut mesin milling.

Mesin milling adalah mesin yang paling mampu melakukan banyak tugas bila dibandingkan dengan mesin perkakas yang lain. Hal ini disebabkan karena selain mampu mesin permukaan datar maupun berlekuk/profil dengan penyelesaian dan ketelitian yang istimiwa, juga berguna untuk menghaluskan atau meratakan benda kerja sesuai dengan dimensi yang dikehendaki.

Mesin milling dapat menghasilkan permukaan bidang rata yang menghasilkan tingkat kekasaran permukaan yang cukup halus, tetapi proses ini membutuhkan pelumas berupa oli yang berguna untuk pendingin mata milling agar tidak cepat aus.

Istilah tingkat kekasaran permukaan digunakan secara luas di industri dan biasanya digunakan untuk mengukur kehalusan/ kekasaran dari suatu permukaan benda. tekstur permukaan adalah pola dari permukaan yang menyimpang dari suatu permukaan nominal. 
penyimpangan Mungkin acak atau berulang yang diakibatkan oleh kekasaran, wavines, lay dan flaws.

kekasaran terdiri dari ketidakteraturan dari tekstur permukaan, yang pada umumnya mencakup ketidakteraturan yang diakibatkan oleh perlakuan selama proses produksi. contoh bentuk tekstur permukaan benda kerja dapat dilihat pada gambar.

Dalam proses pemesinan dituntut untuk menghasilkan hasil produksi kekasaran tertentu yang mana tingkat kekasaran suatu benda semakin kecil semakin bagus dan halus.

kondisi mesin milling yang banyak ditemui di bengkel-bengkel produksi maupun bengkel sekolah /kampus Kejuruaan Teknik Mesin kurang banyak pembaruan, Kebanyakan mesin milling yang digunakan untuk praktek di sekolah atau kampus kejuruan Teknik Mesin sudah uzur dan banyak yang tidak fungsi dengan baik lagi. contoh; kecepatan spindel sudah tidak dapat di setting, feeding tidak dapat disetting, penggerak otomatis sudah tidak berfungsi lagi. hal ini kemungkinan juga tidak hanya dialami oleh sekolah kejuruan saja, mungkin juga dialami oleh bengkel-bengkel produksi. dengan kondisi mesin yang demikian atau tidak normal lagi maka untuk mencapai tingkat kekasaran tertentu perlu cara agar mesin dapat dimaksimalkan.

Selain kondisi di atas penelitian tentang kekasaran permukaan terhadap hasil pemesinan mesin perkakas telah banyak dilakukan, tetapi untuk penelitian tentang faktor yang tidak masuk dalam program belum begitu banyak dilakukan, terutama yang berhubungan dengan posisi pemasangan benda kerja dan posisi pemasangan pahat (endmill).

\section{TUJUAN PENELITIAN}

Tujuan dari penelitian ini adalah:

1. Mengetahui pengaruh tinggi pencekaman benda kerja pada ragum terhadap tingkat kekasaran hasil pemesinan mesin milling.

2. Mengetahui pengaruh tinggi pemasangan endmill cutter terhadap tingkat kekasaran hasil pemesinan mesin milling.

3. Mengetahui pengaruh tinggi pencekaman benda kerja dan tinggi pemasangan endmill cutter yang menghasilkan tingkat kekasaran yang paling kecil.

\section{TINJAUAN PUSTAKA}

Penelitian yang dilakukan ini merujuk pada penelitian Penelitian yang telah dilakukan sebelumnya.

Daniel (2009) meneliti tentang optimasi parameter pemesinan proses CNC frais terhadap hasil kekasaran permukaan dan keausan pahat menggunakan metode taguchi. Dalam penelitian ini metode optimasi yang digunakan dalam penelitian adalah Metode Taguchi dan ANOVA (Analysis of Variance) digunakan untuk mengetahui karakteristik performansi dari parameter pemesinan. Dari hasil optimasi yang telah dilakukan diperoleh bahwa keausan pahat adalah 3,3 $\pm 0,2 \mu \mathrm{m}$ dengan kecepatan putaran spindel $2500 \mathrm{rpm}$, kecepatan pemakanan $0,12 \mathrm{~mm} / \mathrm{rev}$, kedalaman pemotongan $1 \mathrm{~mm}$, dan pendingin minyak.

Giyatno (2009) meneliti tentang optimasi parameter proses pemesinan terhadap keausan pahat dan kekasaran permukaan benda hasil proses CNC turning menggunakan metode Taguchi. Dalam penelitian ini, melalui analisis varian terhadap keausan pahat yang digunakan kecepatan pemakanan memiliki kontribusi paling tinggi terhadap keausan pahat, dan kondisi parameter pemesinan paling baik diperoleh pada kecepatan potong rendah, kecepatan makan rendah, kedalaman pemakanan rendah, dan berpendingin dromus dengan nilai prediksi keausan pahat $3 \pm 2 \mu \mathrm{m}$ dan kekasaran permukaan eksperimen konfirmasi $7 \pm 2 \mu \mathrm{m}$.

Wen-Hsiang Lai (2000) meneliti tentang model kekuatan potong pada operasi end mill. Hasil penelitian ini adalah pengaruh yang paling signifikan terhadap kekuatan adalah ketebalan 
chip (Tc). Radius dinamis yang disebabkan oleh lari keluar cutter dan kemiringan merupakan titik kunci untuk mempengaruhi ketebalan chip. Pengaruh pemakanan per flute pada kekuatan pemesinan terlihat ketika feedrate meningkat, ketebalan chip seketika juga meningkat, dan kekuatan juga meningkat. Kedalaman radial dan aksial memotong mempengaruhi lebar dan panjang bidang kontak masing-masing. Artinya, ketika kedalaman radial dan aksial memotong meningkat, bidang kontak meningkat, dan kekuatan menjadi lebih besar. Ketika depth of cut meningkat, kekuatan juga meningkat. Selanjutnya, kekuatan X diukur berubah dari nilai-nilai negatif ke nilai positif ketika kedalaman radial potong berubah dari $25 \%$ menjadi $75 \%$.

Yong-hyun kim, sung-lim ko (2002) meneliti tentang pengembangan desain dan teknologi manufaktur untuk end mills pada proses pemesinan baja liat. Hasil penelitian ini adalah (1) program simulasi untuk flute heliks grinding dikembangkan dan diterapkan pada desain dan pembuatan mill end dengan memprediksi konfigurasi potong lintang. (2) rake angle yang optimal dan ditentukan sudut clearance, mengingat perubahan dalam permukaan yang salah dalam uji kinerja sesuai dengan perubahan dalam geometri. (3) seluruh proses untuk desain dan pembuatan end mill dengan kinerja pemotongan tinggi disarankan berdasarkan program simulasi flute heliks grinding

Kivanc \& Budak (2004) pemodelan struktural end mill untuk kesalahan bentuk dan bentuk analisis stabilitas. Hasil penelitian ini adalah sifat dinamis dan statis dari milling yang sangat penting untuk presisi mesin dan stabilitas pemotongan. Metode analisis eksperimen yang digunakan untuk menentukan karakteristik ini. Hasil eksperimenini tidak memberikan informasi yang akurat terutama untuk dinamika dan stabilitas pemotongan. Metode eksperimental, di sisi lain, memakan waktu jumlah kemungkinan kombinasi pemegang tool dan tool, geometri alat dan material dalam pengaturan industri. Model analisis yang disajikan dalam karya ini menghilangkan kebutuhan untuk pengukuran fungsi transfer untuk setiap perakitan alat. Model mempertimbangkan geometri kompleks flute dalam pengembangan properti pemotongan melintang. Endmills memiliki flute dan bagian unfluted, yang semakin mempersulit geometri mereka. Karakteristik ini tersegmentasi juga telah dipertimbangkan dalam pemodelan statis dan dinamis. RCSA model telah digunakan untuk menggabungkan dinamika diukur dari pemegang alat / spindel dan mode akhir analitis ditentukan mill. Prediksi baik statis dan dinamis yang dibuktikan sangat akurat. Pendekatan yang disajikan di sini sangat berguna untuk implementasi dalam sistem mesin virtual di mana kesalahan bentuk dan batas stabilitas untuk aplikasi milling dapat ditentukan secara otomatis.

Lou, Chen, dan Li (1999) meneliti tentang teknik perkiraan kekasaran permukaan pada CNC milling. Hasil penelitian ini adalah Kekasaran permukaan ( $\mathrm{Ra})$ dapat diprediksi secara efektif oleh menerapkan kecepatan spindle, kecepatan pemakanan, kedalaman potong, dan interaksi dalam beberapa model regresi. Model regresi bisa memprediksi permukaan kekasaran (Ra) dengan rata-rata penyimpangan 9,71\% atau 90,29\% akurasi dari pelatihan kumpulan data. Model regresi bisa memprediksi permukaan kekasaran $(\mathrm{Ra})$ dari data pengujian ditetapkan yang tidak termasuk dalam analisis regresi berganda dengan persentase rata- rata penyimpangan 9,97\% atau akurasi 90,03\%. Laju pemakanan adalah yang paling signifikan sebagai parameter pemesinan yang digunakan untuk memprediksi kekasaran permukaan dalam model regresi berganda.

Dari penelitian-penelitian di atas, variabel yang menyebabkan kekasaran permukaan adalah penggunaan variasi parameter pemesinan, jenis perlakuan pemesinan yang kurang optimal dan geometri pahat. Oleh karena itu, penelitian ini mengambil variabel perlakuan posisi dan pencekaman baik spesimen maupun pemasangan endmill untuk mengetahui kondisi paling optimal terhadap tingkat kekasaran permukaan. 


\section{METODOLOGI PENELITIAN}

Diagram alir penelitian

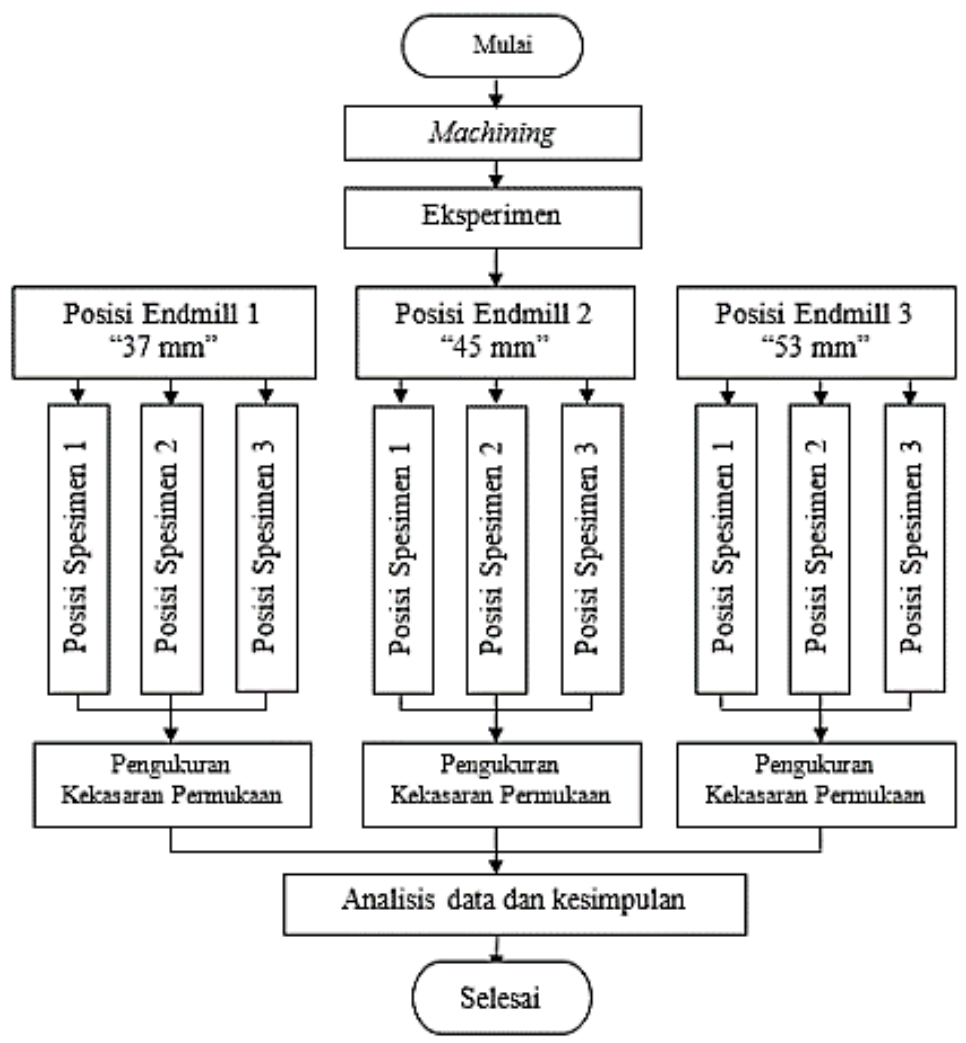

Gambar 1.Diagram Alir Penelitian

HASIL DAN PEMBAHASAN

Pembahasan Pengukuran Hasil Tingkat Kekasaran Permukaan Baja ST 40 Hasil Pemesinan Milling.

Dalam pembahasan hasil penelitian ini meliputi hasil pengukuran kekasaran permukaan interaksi antara tinggi pencekaman spesimen dan tinggi pemasangan endmill terhadap collet.

\section{Tinggi Pencekaman Spesimen.}

Rerata hasil pengukuran kekasaran permukaan baja ST 40 dilihat pada tabel 1. tabel 1 diubah dalam bentuk grafik, sehingga akan memudahkan untuk melakukan analisis hasil.

Tabel 1. Data Hasil Pengukuran Tingkat Kekasaran Baja ST 40 ( Dalam $\mu \mathrm{m}$ ).

\begin{tabular}{cccc}
\hline Tinggi Pencekaman & \multicolumn{3}{c}{ Tinggi Pencekaman Benda Kerja } \\
\cline { 2 - 4 } Endmill & $10 \mathrm{~mm}$ & $17 \mathrm{~mm}$ & $24 \mathrm{~mm}$ \\
\hline $37 \mathrm{~mm}$ & 2,001 & 1,199 & 1,730 \\
$45 \mathrm{~mm}$ & 1,584 & 0,939 & 1,484 \\
$53 \mathrm{~mm}$ & 1,864 & 1,318 & 2,206 \\
\hline
\end{tabular}

Berdasarkan tabel 1 data tingkat kekasaran permukaan benda kerja Proses pemesinan milling pada baja ST 40 dengan dua kondisi pemakanan dari pengaruh tinggi pencekaman benda kerja Dapat dideskripsikan seperti pada gambar 2. 


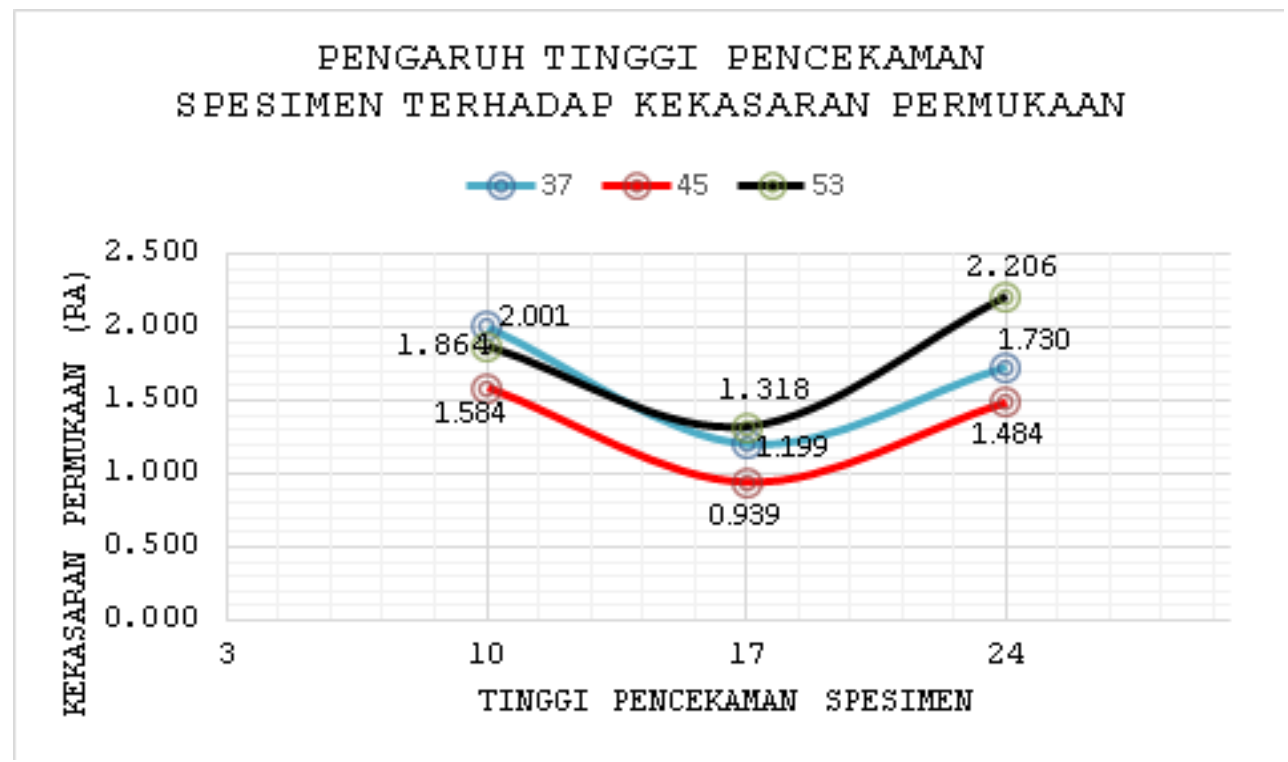

Gambar 2. Diagram Tinggi Pencekaman Benda Kerja- Ra

Pada gambar 2 didapat nilai kekasaran paling kecil terjadi pada interaksi tinggi pencekaman benda kerja $17 \mathrm{~mm}$ dengan tinggi pencekaman endmill cutter $45 \mathrm{~mm}$ yaitu sebesar 0,939 mikrometer, sedangkan tingkat kekasaran paling besar terjadi pada interaksi tinggi pencekaman benda kerja $24 \mathrm{~mm}$ dengan tinggi pencekaman Endmill cutter $53 \mathrm{~mm}$ yaitu sebesar 2,206 mikrometer.

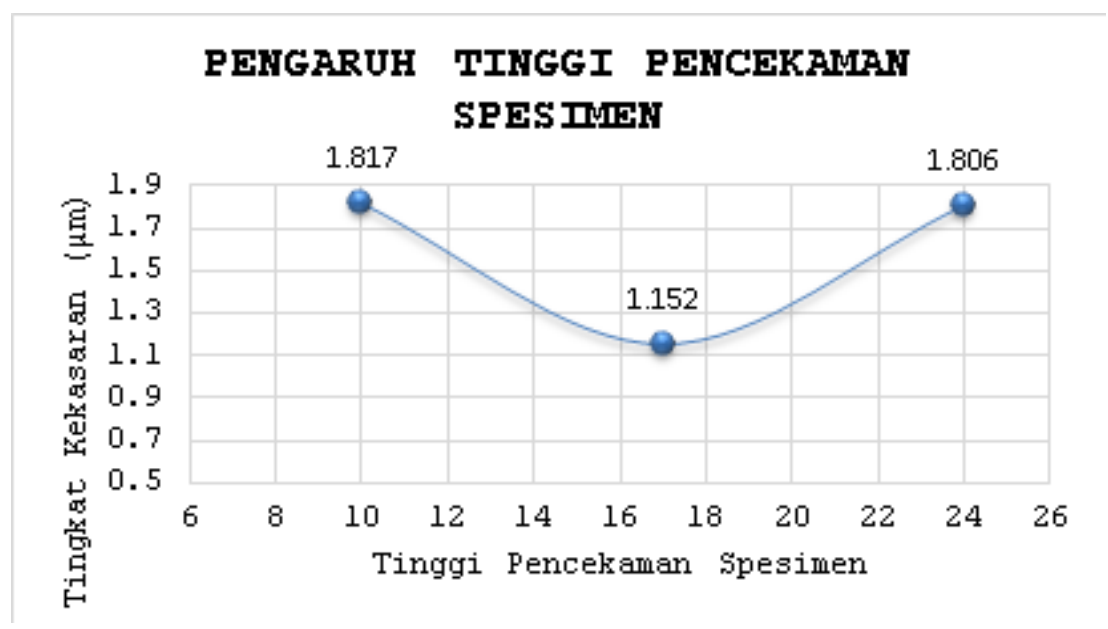

Gambar 3. Rerata Ra Terhadap Tinggi Pencekaman Spesimen

Berdasar gambar 3 yang diambil pada tabel 1. didapat rata-rata tingkat kekasaran berdasar tinggi pencekaman benda kerja, yakni; untuk tinggi pencekaman benda kerja terhadap ragum $10 \mathrm{~mm}$ didapat kekasaran rata-rata ( $\mathrm{Ra}$ ) 1,817 mikrometer, untuk tinggi pencekaman benda kerja terhadap ragum $17 \mathrm{~mm}$ didapat Ra 1,152 mikrometer, dan untuk tinggi Pencekaman benda kerja terhadap ragum $24 \mathrm{~mm}$ didapat $\mathrm{Ra}$ 1,806 mikrometer.

Uraian pada gambar 2 dan gambar 3 di atas dapat diambil kesimpulan bahwa Ra paling kecil paling kecil didapat dari tinggi pencekaman benda kerja terhadap ragum $17 \mathrm{~mm}$. yakni sebesar 1,152 mikrometer, lebih tepatnya berada pada interaksi tinggi pencekaman benda kerja $17 \mathrm{~mm}$ dengan tinggi pencekaman endmill cutter $45 \mathrm{~mm}$ yaitu sebesar 0,939 mikrometer. Sedangkan Ra paling besar didapat dari tinggi pencekaman benda kerja terhadap ragum 10 
mm didapat tingkat kekasaran rata-rata 1,817 mikrometer, tetapi interaksi yang menghasilkan tingkat kekasaran yang paling besar adalah interaksi pencekaman benda kerja $24 \mathrm{~mm}$ dengan tinggi pencekaman endmill cutter $53 \mathrm{~mm}$ yaitu sebesar 2,206 mikrometer.

\section{Tinggi Pencekaman Endmill.}

Dasarkan tabel 1 data tingkat kekasaran permukaan benda kerja Proses pemesinan milling pada baja ST 40 dengan dua kondisi pemakanan dari tinggi pencekaman endmill dapat dideskripsikan seperti pada gambar 4 di bawah ini:

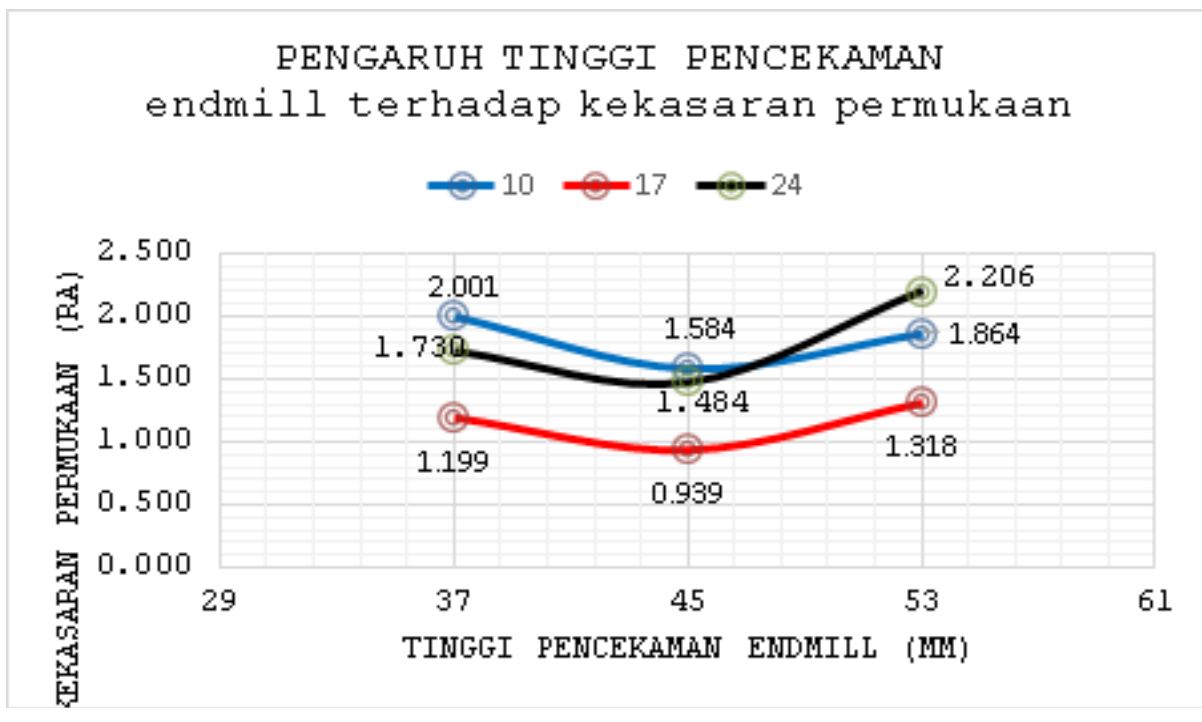

Gambar 4. Diagram Tinggi Pencekaman Endmill- Ra

Pada gambar 4 didapat nilai kekasaran paling kecil terjadi pada interaksi tinggi pencekaman benda kerja $17 \mathrm{~mm}$ dengan tinggi pencekaman endmill cutter $45 \mathrm{~mm}$ yaitu sebesar 0,939 mikrometer, sedangkan tingkat kekasaran paling besar terjadi pada interaksi tinggi pencekaman benda kerja $24 \mathrm{~mm}$ dengan tinggi pencekaman endmill cutter $53 \mathrm{~mm}$ yaitu sebesar 2,206 mikrometer.

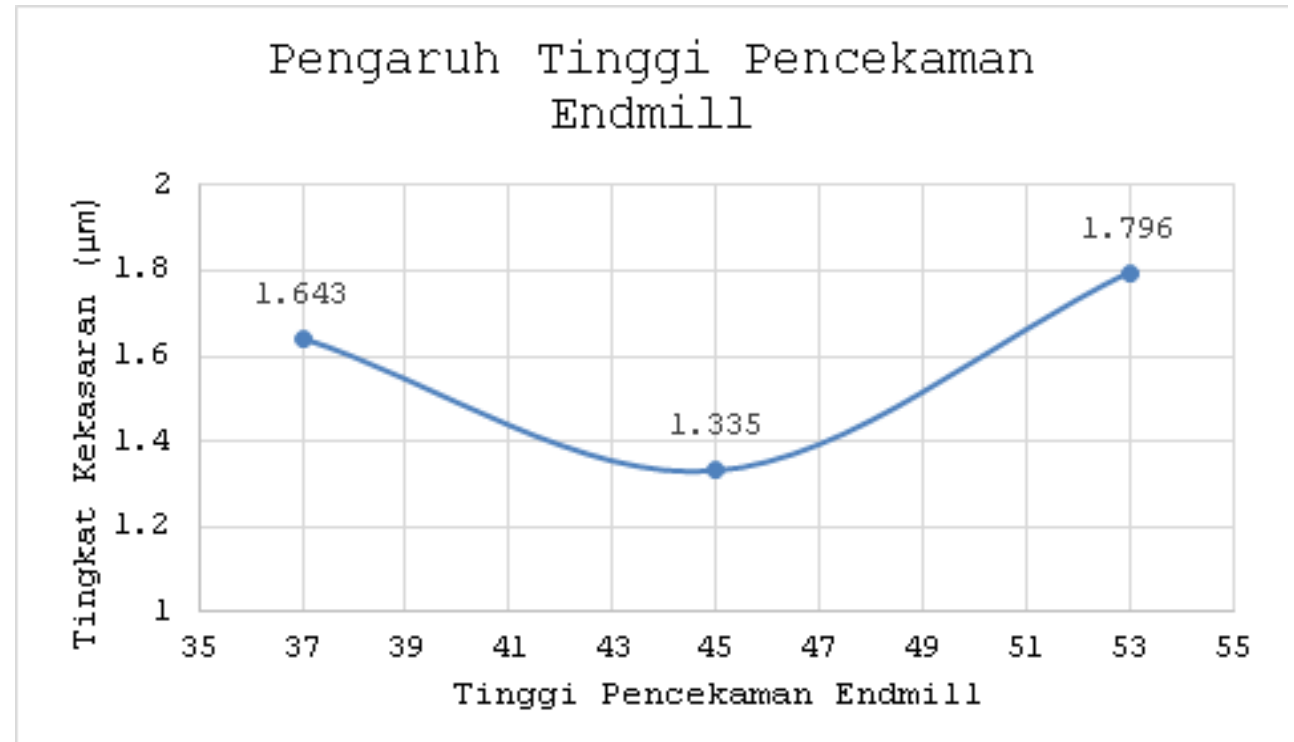

Gambar 5. Rerata Ra Terhadap Tinggi Pencekaman Endmill 
Berdasar gambar 5 didapat rata-rata tingkat kekasaran berdasar tinggi pencekaman endmill, yakni; untuk tinggi pencekaman endmill $37 \mathrm{~mm}$ didapat Ra 1,643 mikrometer, untuk tinggi pencekaman endmill $45 \mathrm{~mm}$ didapat Ra 1,335 mikrometer, dan untuk tinggi pencekaman endmill $53 \mathrm{~mm}$ didapat Ra 1,796 mikrometer.

Uraian pada gambar 4 dan gambar 5 di atas dapat diambil kesimpulan bahwa Ra paling kecil didapat dari tinggi pencekaman endmill $45 \mathrm{~mm}$ yakni sebesar 1,335 mikrometer, lebih tepatnya pada interaksi tinggi pencekaman benda kerja $17 \mathrm{~mm}$ dengan tinggi pencekaman endmill cutter $45 \mathrm{~mm}$ yaitu sebesar 0,939 mikrometer.

Sedangkan Ra paling besar didapat pada tinggi pencekaman endmill $53 \mathrm{~mm}$ didapat Ra 1,796 mikrometer, lebih tepatnya ada pada interaksi tinggi pencekaman benda kerja $24 \mathrm{~mm}$ dengan tinggi pencekaman endmill cutter $53 \mathrm{~mm}$ yaitu sebesar 2,206 mikrometer.

\section{KESIMPULAN}

Berdasarkan hasil penelitian, maka dapat disimpulkan beberapa hal sebagai berikut;

1. Ada pengaruh yang signifikan dari pengaruh tinggi pencekaman benda kerja pada ragum terhadap tingkat kekasaran hasil pemesinan mesin milling. Tinggi pencekaman benda kerja terhadap ragum $10 \mathrm{~mm}$ didapat tingkat kekasaran rata-rata $(\mathrm{Ra})$ 1,817 mikrometer, untuk tinggi pencekaman $17 \mathrm{~mm}$ didapat Ra 1,152 mikrometer, dan untuk tinggi pencekaman 24 mm didapat $\mathrm{Ra} 1,806$ mikrometer.

2. Ada pengaruh yang signifikan dari pengaruh tinggi pemasangan endmill cutter terhadap tingkat kekasaran hasil pemesinan mesin milling. Tinggi pencekaman endmill $37 \mathrm{~mm}$ didapat ra 1,643 mikrometer, tinggi pencekaman endmill 45mm didapat Ra 1,335 mikrometer, dan untuk tinggi pencekaman endmill $53 \mathrm{~mm}$ didapat Ra 1,796 mikrometer.

3. Tingkat kekasaran baja ST 40 yang paling kecil didapat dari tinggi pencekaman endmill $45 \mathrm{~mm}$, lebih tepatnya pada interaksi tinggi pencekaman benda kerja $17 \mathrm{~mm}$ dengan tinggi pencekaman endmill cutter $45 \mathrm{~mm}$ yaitu sebesar 0,939 mikrometer. Sedangkan Ra paling besar didapat dari tinggi pencekaman endmill $53 \mathrm{~mm}$ yaitu pada interaksi tinggi pencekaman benda kerja $24 \mathrm{~mm}$ dengan tinggi pencekaman endmill cutter $53 \mathrm{~mm}$ yaitu sebesar 2,206 mikrometer.

4. Tingkat kekasaran pada tinggi pencekaman endmill menunjukkan bahwa semakin mendekati flute maka akan semakin kasar karena ada rongga flute yang tidak tercekam, dan pencekaman semakin ke atas dari panjang endmill juga akan semakin kasar karena terjadi vibrasi yang besar saat proses pemakanan, rekomendasi dari penelitian ini agar mendapat nilai kekasaran yang optimal adalah memasang pahat di antara batas tengah panjangnya endmill sampai ke batas flute pada endmill.

\section{SARAN}

Berdasarkan hasil penelitian yang diperoleh, maka dapat disampaikan saran-saran sebagai berikut:

1. Untuk penelitian selanjutnya yang sejenis sangat baik kalau di analisis faktor-faktor atau variabel variabel yang lain yang mempengaruhi tingkat kekasaran baja ST 40 hasil pemesinan dengan mesin milling, misalnya diameter pahat, jenis pendingin, dan kekerasan pahat.

2. Untuk penelitian selanjutnya yang sejenis sangat baik kalau mencoba memilih mesin CNC milling untuk proses pemesinannya.

3. Selain hal di atas, bagi peneliti yang akan mengadakan penelitian yang relevan di masa mendatang diharapkan hasil penelitian ini dapat dijadikan sebagai bahan masukan dan pertimbangan dalam melakukan penelitian. 


\section{DAFTAR PUSTAKA}

Daniel. 2009. Optimasi Parameter Pemesinan Proses CNC Frais Terhadap Hasil Kekasaran Permukaan dan Keausan Pahat Menggunakan Metode Taguchi. Semarang: Tugas Sarjana Jurusan Teknik Mesin Universitas Diponegoro.

Giyatno. 2009. Optimasi Parameter Proses Pemesinan Terhadap Keausan Pahat Dan Kekasaran Permukaan Benda Hasil Proses CNC Turning dengan Menggunakan Metode Taguchi. Semarang: Tugas Sarjana Jurusan Teknik Mesin Universitas Diponegoro.

Kim, Hyun \& Ko, Lim. 2002. Development of Design and Manufacturing Technology for End Mills Machining Hardened Steel. Journal of Material Processing Technology 130- 131

Kivanc V.B \& Budak, E. 2004. Structural Modeling of Animal for Form Error and Stability Analysis. International Journal of Machine Tools and Manufacture 44( 2004) 1151- 1161

Lou, S.M., Chen, C.J. \& Li,M.C. 1999. Surface Roughness Prediction Technique for CNC End-Milling. International Journal of Industrial Technologi Volume 15, 1999.

Wen-Hsiang Lai. 2000. Modeling of Cutting Forces in End Milling Operations. Journal of Science and Engineering, Vol. 3, No.1, pp. 15-22. 